\title{
Guidelines for health and welfare monitoring of fish used in research
}

\author{
R Johansen ${ }^{1}$, J R Needham ${ }^{1,2}$, D J Colquhoun ${ }^{3}$, T T Poppe ${ }^{4}$ and A J Smith ${ }^{1}$ \\ ${ }^{1}$ Norwegian School of Veterinary Science, Laboratory Animal Unit, PO Box 8146 Dep., 0033 Oslo, \\ Norway; ${ }^{2}$ The Microbiology Laboratories, North Harrow, Middlesex HA2 7RE, UK; ${ }^{3}$ Section of Fish \\ Health, National Veterinary Institute, PO Box 8156 Dep., 0033 Oslo, Norway; ${ }^{4}$ Department of Basic \\ Sciences and Aquatic Medicine, Norwegian School of Veterinary Science, PO Box 8146 Dep., 0033 Oslo, \\ Norway
}

\section{Summary}

The aim of this paper is to provide background material necessary for the development of international guidelines for the health and welfare monitoring of fish used in research. It provides an overview of present guidelines and discusses why more detailed and speciesspecific guidelines are needed. A major issue within fish research is to document the situation today and point out areas where improvements are needed.

Keywords Fish; health; welfare; monitoring; guidelines

Guidelines for monitoring and reporting the general health status and welfare of fish used in research are sparse compared with those available for mammalian laboratory animals. Despite the fact that there are more fish species than all other vertebrate species combined and that fish are studied in almost all biological disciplines (Powers 1989), most guidelines for fish encompass all species and all types of research (Casebolt et al. 1998). There is a great need for more speciesspecific guidelines for health and welfare monitoring. In some cases, these guidelines may also have to be specific to the scientific topic where they are to be used.

The number of fish used in research is increasing, due both to the rapid expansion in the fish farming industry and an increased use of fish as model organisms in basic research and chemical testing (Kane et al. 1996). The debate on whether to use fish or mice models started over 25 years ago (Dawe \& Couch 1984). Rodent models are now frequently being replaced by fish models
(May et al. 1987a, Powers 1989, DeTolla et al. 1995).

Guidelines and legislations are often more liberal towards the use of fish than mammals. This can be illustrated by the lack of focus on humane endpoints in fish models (Ryder 2005). $\mathrm{LD}_{50}$ testing is, for example, no longer allowed on mammals, but remains in use for fish (Braunbeck et al. 2004).

Even the reporting of numbers of fish used, and the type of research for which they are used, is confused by a lack of common international practice. Harmonization in this field is important to avoid the transfer of research from countries with high standards to those with lower ones. In Europe, all fish species and sizes are reported in the same statistical groups and the research disciplines reported are very general. Figure 1 shows, for example, an analysis of the use of live fish in Norway in 2004. This makes it difficult to monitor what fish are actually used for in research.

Reporting of the health and welfare of fish used in research is often sparse (Brattelid \& Smith 2000), and may include general statements such as 'Healthy fish from a 


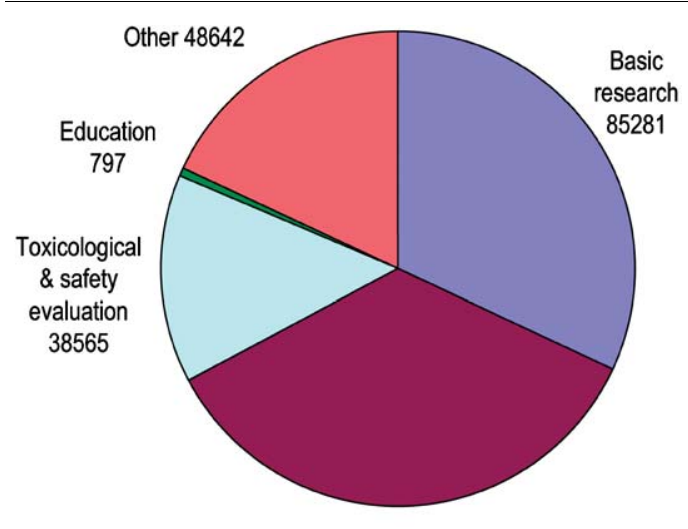

$R \& D 94090$

Figure 1 A simple breakdown of the number of live fish used for research in Norway 2004. Actual numbers are provided in parentheses. Most fish were reported as having been used in the categories 'Basic research' and 'Research and Development' (R\&D). More details of the type of testing for which the fish were actually used cannot be obtained from the statistics

commercial fish farm were randomly sampled for the experiment'. How the health was monitored is often not stated. Information relating to health monitoring during the experimental trial may also be sparse, often limited to statements such as 'no clinical signs of disease were observed'. In most trials, no necropsies or tests are performed to determine the health status.

It is important to note that there is no international consensus on animal welfare legislation, and fish are often not included in national laws. Some general guidelines for monitoring of laboratory animals may also be useful for fish (Grossblatt 1996). General considerations relevant to fish include selection of the appropriate species, identification of the minimum number of animals required for valid results, suitable living conditions and the use of experienced personnel including fish health specialists. The search for alternatives is as relevant in fish as in mammals, but in vitro methods in fish research are sparse.

Researchers are ethically bound to produce as much knowledge as possible from each animal used. Lack of standardization of parameters such as genotype, water quality and handling procedures often leads to incomparable results and therefore the unnecessary use of large numbers of fish. Harmonization of health and welfare monitoring is one important factor in the process of standardization that is needed to reduce fish numbers in research.

Laboratory animal units may be accredited by the Association for Assessment and Accreditation of Laboratory Animal Care (AAALAC) who rely on widely accepted guidelines for the care and use of laboratory animals (Grossblatt 1996). Recommendations for health monitoring of rodents, rabbits, cats and other mammalian animals have been established by the Federation of European Laboratory Animal Science Associations (FELASA) (Rehbinder et al. 1998, Nicklas et al. 2002). These publications include lists of infectious agents to be tested for, suggested methods for testing and a standardized report form. Widely accepted guidelines for the care and use of fish in research are, however, not currently available.

The most recent and thorough guidelines for fish are provided by the Canadian Council on Animal Care (http:// www.ccac.ca, Guidelines on the care and use of fish in research, teaching and testing). These guidelines are general ones for all fish species in all types of research and provide recommendations for, among other things, facilities, management and husbandry. The section on health monitoring focuses on establishing programmes for disease detection, written agreements with fish health professionals and the strategic use of disease control measures. Detailed healthmonitoring protocols are not outlined, although there is a table of clinical signs of disease to be monitored.

Current guidelines usually leave it up to the local fish health specialists to determine how health and welfare should be monitored and which fish should be allowed into the research facility (UFRC 2004, CCAC 2005, Council of Europe 2006). In textbooks on the care and use of classical laboratory fish, such as zebrafish, health monitoring is often limited to statements about the prevalence of diseases and how they can be prevented (Ostrander 2000, Westerfield 2000). Few or 
no instructions are provided on what investigations should be performed before fish are approved for research and how the findings should be interpreted and reported. Standardization of health and welfare monitoring is one important part of the harmonization process that is needed to obtain research results that are comparable between research facilities. Fish health specialists need, therefore, internationally accepted guidelines to ensure that the monitoring of health and welfare follows certain standards.

A collection of guidelines for the care and use of fish in research is available at http:// oslovet.veths.no/fish. The aim of the present paper is to provide an overview of current guidelines on health and welfare monitoring, together with a checklist of points to be considered when species-specific guidelines are developed. This paper will point out why the monitoring of health and welfare in fish is so important, but also illustrate how limitations in our present knowledge make monitoring difficult. Present and future possibilities are discussed, including the need for specific guidelines for different research disciplines.

\section{General considerations}

Even if no infectious agent or disease is detected, the health status of different fish groups may vary considerably. An overview of the phylogenetic background of the fish, including factors such as environmental monitoring and vaccination programmes, should be documented to provide the best possible picture of health status.

Ideally, experimental fish should be free from infectious agents and stress, but this is seldom possible, especially when using farmed fish. Whether the presence of an infectious agent will result in clinical disease is influenced by the general health status of the fish, which in turn is highly influenced by factors in the environment such as water temperature and oxygen levels (Figure 2). Subclinical infections are quite common in fish and the effects of such infections on experimental results are often not known. The question is often not whether an infectious agent is present or

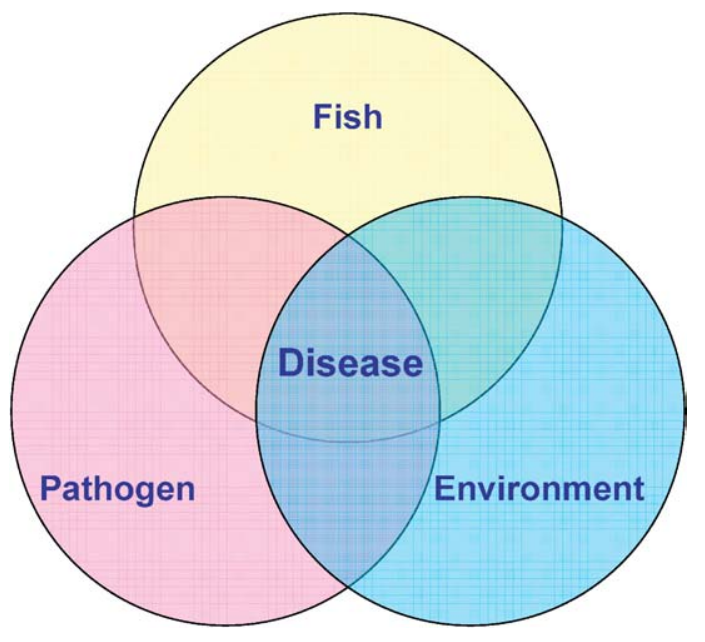

Figure 2 The relationships between fish, pathogens and the environment. Some pathogens may cause a disease even if the environment is suitable, but suboptimal environmental factors may trigger an infectious disease. Diseases may even be caused by poor environmental factors alone

not, but how it influences the health of the fish and thereby the result of the trial. Even if the effect of a health problem, infectious agent or suboptimal condition is unknown, they should be reported to provide a total picture of the research situation. This is important for comparison and interpretation of research results.

Due to the lack of non-invasive test methods, health monitoring in fish is normally performed on populations. It is therefore important to obtain representative samples of the population. If the prevalence of the disease is low and/or the sensitivity of the diagnostic test is low, the number of fish that have to be killed for examination may become too high to perform the test before the onset of the trial. Testing of experimental fish must therefore often be done at the end of the trial and interpretation of the results may then be difficult. In the worst case, the examination may show that the fish already used in the trial were not suitable, and the research results invalid.

There is no doubt that the health status and wellbeing of the research animal may have a major effect on research results (Melby \& Balk 1983). A history of the animals' health and welfare throughout their 
life will reveal more than tests at the time of the research. Health and welfare monitoring of research fish should therefore start with broodstock and eggs, and continue until the research is finished. This could be achieved by introducing a health card system similar to that used in livestock production in some countries.

Knowledge of the cause and source of disease is of major importance in health monitoring, but is often sparse. The discovery of new fish diseases each year adds to the problem. Specific guidelines must therefore be updated continuously to adapt to new knowledge that may include health issues, detection methods, medical treatment and the spread of pathogens. The availability of these guidelines on the Internet, allowing continuous updating, should therefore be considered.

\section{Selection of fish}

Factors to consider when selecting fish for research include, in addition to the health status, species, strain, size, weight and number of fish. Different types of research may need different requirements for health monitoring prior to selection of fish.

Identification of epidemiological risk factors may be useful when selecting farms, and health documentation including disease history, vaccination strategies and treatments need to be evaluated in relation to the aims of the investigation.

For studies on farmed fish, a representative selection from the population is often used, and this makes it easier to interpret the research results. However, there are some advantages in establishing models using smaller laboratory fish to investigate problems in farmed fish and recently a few such models have been developed (LaPatra et a1. 2000). Our basic knowledge of the health, genomics and embryology of the most common laboratory fish species, such as zebrafish (Danio rerio) and medaka (Oryzias latipes), is more advanced than in farmed fish species, and this makes them useful in a wide range of research models (Powers 1989, Casebolt et al. 1998, Ostrander 2000, Alestrom 2004).
Comparison of results between trials is therefore much easier when using laboratory fish species, but the interpretation of the results in relation to farmed fish is still difficult. Extrapolation of results from rodent models to human health is possible based upon many years of experience, but similar knowledge on how to extrapolate the results from, for example, zebrafish to salmonids does not yet exist (Phelan et al. 2005).

Good production results alone do not constitute an adequate measurement of the health and wellbeing of the animals. Figure 3 shows two Atlantic halibut of the same age, but of totally different size, emphasizing the need for both age and size to be considered as selection criteria. Halibut with high growth rates have been shown to have a much higher prevalence of epicarditis than fish with a lower growth rate (Johansen \& Poppe 2002).

Heritability of disease resistance in fish has been shown for bacteria (Gjedrem \& Gjøen 1995), viruses (Okamoto et al. 1993), fungi (Nilsson 1992) and parasites (Kolstad et al. 2005). Breeding programmes in, for example, Atlantic salmon have led to increased disease resistance in each generation. Challenge models established in one generation of fish may therefore not provide the same results in the next generation (Johansen L-H, personal communication). Resistance to different agents may be independent of each other or may be positively or negatively correlated.

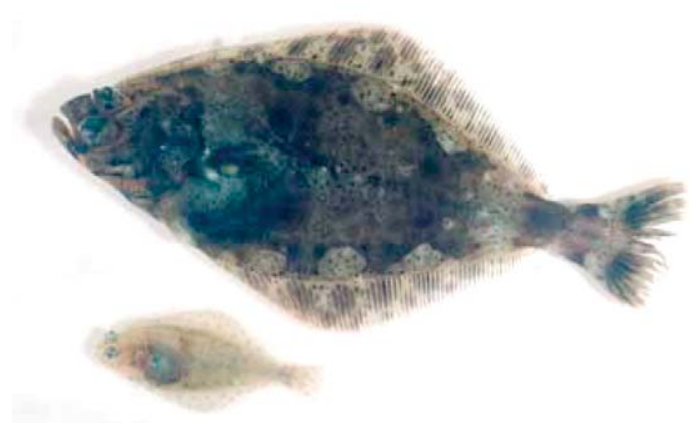

Figure 3 Atlantic halibut Hippoglossus hippoglossus from a commercial fish farm in Norway. This photograph illustrates that fish of the same age (12 months) may be of totally different sizes ( 2 and $40 \mathrm{~g}$ ) 
Basic knowledge of the link between genotype and disease resistance in fish is sparse, but molecular methods are now being used to provide an insight into this important field (Grimholt et al. 2003).

Any genetic manipulation, such as the production of an all-female population, must be reported and its influence on the research results assessed (Thorgaard 1986). The acute stress response has, for example, been shown to differ between diploid and triploid fish (Benfey \& Biron 2000).

Most of the current guidelines for health monitoring of fish in research focus on quarantine of new arrivals to the research facility (DeTolla et al. 1995, Poole 1999, Schwedeler \& Johnson 2000). There is great variation in the guidelines on how infectious agents or diseases should be treated once they are detected. Some state that the fish should be free of notifiable diseases (UFRC 2004, CCAC 2005). Diseases considered notifiable vary between countries (DEFRA 2003) and international notifiable fish diseases are few (OIE 2005). Few guidelines provide lists of common diseases that should be investigated (Casebolt et al. 1998). One set of guidelines for the use of aquatic species, among a collection of resources for Institutional Animal Care and Use Committees (http://www.nal.usda.gov/ awic/pubs/Fishwelfare/iacuc.htm), recommends salt treatment and, if ineffective, antibiotic therapy, of diseased fish before a trial rather than exclusion of these stocks from research (http:// www.research.psu.edu/orp/areas/animals/ policies/guide10.pdf). These examples illustrate the lack of harmonization of criteria for allowing fish into research facilities.

In most cases, guidelines merely state that quarantined fish should be monitored for clinical signs of disease and if a disease problem occurs, a fish health specialist should be contacted for advice. The length of the quarantine period is often left up to the fish health specialist (CCAC 2005). As long as these specialists are not provided with generally accepted guidelines, the recommendations they give may vary considerably.

\section{The environment}

Physical water parameters are numerous and fish are influenced by their environment to a much greater degree than mammals. Optimal ranges for water parameters may vary between different fish species and between the various developmental stages. It is therefore important that researchers and technical staff have knowledge of the appropriate environmental needs for the specific group of fish with which they are working. Some general recommendations that are applicable to most fish species are available (May et al. 1987b, Klontz 1995, Schwedeler \& Johnson 2000).

An overview of our knowledge on the care and use of fish as laboratory animals was published by Casebolt et al. (1998). They identified water quality as the single most important element for maintaining healthy animals and ensuring valid experimental results. Efforts should be made to keep all parameters within acceptable ranges, in order to reduce stress. Fish have the ability to adapt to some changes in water quality without stress and these ranges are characterized as acceptable limits. However, rapid changes, even within an acceptable range, may cause stress and should therefore be avoided. Although fish may cope with suboptimal conditions for a short time by increased energy use, longer exposure may lead to chronic stress. Measurements of water parameters, including their fluctuations and the duration of these, must therefore be documented.

The main water quality parameters are temperature, oxygen saturation, nitrogen compounds, carbon dioxide, $\mathrm{pH}$ and salinity. A change in one of these factors may lead to fluctuation of the other parameters. Other environmental parameters such as light and noise levels also need to be considered.

\section{Temperature}

With the exception of a few species such as tuna, fish have the same body temperature as the surrounding water. Maintenance of temperature within an optimal range is therefore of major importance and any 
change should be made gradually. The standard environmental temperature (SET) is defined as the water temperature the fish would themselves select if given the opportunity to do so. For each degree below SET there is a decrease in metabolic rate, and for each degree above SET there is a reduction in feed conversion rate.

Oxygen solubility decreases with increasing temperature, thereby reducing the ability of haemoglobin to bind oxygen. Increased temperature may also increase metabolism, stress levels, physical activity, appetite, growth and other parameters that increase oxygen demand. Supplementary water aeration during periods of increased temperature may therefore be required.

Temperature also has a major effect on ionic balance through changes in membrane pumping capacity. Fish are dependent upon this to maintain osmotic equilibrium.

Freshwater fish may therefore become hypoosmotic, and saltwater fish hyperosmotic, at low temperatures.

\section{Oxygen and other gas levels}

Both oxygen levels and oxygen demand vary with temperature. Factors including stocking density, water flow and handling stress are of major importance when calculating the level of oxygen saturation required.

Supersaturation of water with oxygen or other gases may result in problems with gasbubble disease. Physoclistous fish such as Atlantic cod (Gadus morhua) have no connection between the gut and the swimbladder and are therefore very sensitive to changes in saturated gas levels.

\section{Nitrogen compounds}

Urea, faeces and feed in the water are converted into ammonia and then into nitrite and nitrate. Nitrogen compounds are toxic to fish and sufficient water flow to remove these compounds is therefore important. This is particularly a potential problem in recirculation systems.

Unionized ammonia is the most toxic form in fish and its presence is dependent upon $\mathrm{pH}$, salinity and temperature.

Ammonia problems are best avoided by reducing the density of fish and by reducing water temperature. Good filtration and water changes also help to keep ammonia levels at an acceptable level, particularly in static systems. Younger fish are in general more susceptible than older fish, while marine fish are more susceptible than freshwater fish.

\section{Carbon dioxide and $p H$}

As in mammals, respiration in fish produces carbon dioxide $\left(\mathrm{CO}_{2}\right)$. When additional oxygen is used to solve problems related to high fish densities or low water flow, high levels of $\mathrm{CO}_{2}$ may result, with a subsequent fall in $\mathrm{pH}$, causing further knock-on effects in water chemistry. Water supplies should be buffered if necessary.

\section{Salinity}

Although some fish have a wide salinity tolerance, changes in salinity must be gradual to enable the fish to adapt and avoid stress. Salinity has a major effect on many physiological parameters in fish and may therefore have a major effect on the outcome of the research.

\section{Light}

Photoperiod has a major effect on physiology and behaviour in most fish species. Light manipulation is often used in fish farming to manipulate maturation, increase appetite and stimulate weight gain. Researchers should therefore consider the possible effects of photoperiod both prior to and during the experiment, particularly if the research involves changing the timing of the light-dark cycle. In addition, bright light is aversive to many fish, so the provision of areas offering shade should be considered.

\section{Noise and vibrations}

Sound is transmitted very efficiently in water and fish have a highly developed detection system. Unnecessary noise or vibration in the experimental facility should 
therefore be avoided where possible. As fish may become adapted to certain background noise and vibrations, it is important that any changes be kept to a minimum during the experiment.

\section{Holding facilities}

Different fish species and sizes have different requirements for, among other parameters, stocking density, water flow and feeding regime. The aim should be to provide the fish with an environment allowing as normal a behaviour as possible with a minimum of stress and aggression.

\section{Density of fish}

The space provided per fish has a major effect on other environmental factors. High fish densities necessitate holding facilities capable of a high degree of environmental control. High density may cause stress in the fish even if other environmental factors are within acceptable limits. Density control is therefore often mentioned as one of the major factors influencing welfare of salmonids (Lymbery 2002). Preferred density varies extensively between different fish species and it is also important to remember that low density can lead to stress, especially in fish that normally form shoals.

\section{Infectious agents}

Lists of infectious agents for different fish species have been published in several textbooks (Ferguson 1989, Roberts 1989, Ostrander 2000, Winton 2001). New pathogens are constantly being discovered and our knowledge of known pathogens is increasing all the time. Lists of pathogens and optimal detection methods are therefore a prerequisite for health monitoring. The Zebrafish Information Network (http:// www.zfin.org) provides such service information for zebrafish, and similar Websites for other fish species are needed.

The Office International des Epizooties (OIE) provides a list of notifiable fish diseases and monitors their global incidence (OIE 2005), as well as an overview of standard diagnostic tests (OIE 2003). There are presently only 16 fish pathogens notifiable to OIE, but since all of these may cause serious disease, they are unacceptable in fish research.

The validation of detection methods and knowledge of the possibilities and limitations of the tests used are major factors to take into account when interpreting results. Knowledge of the sensitivity and specificity of the test, in combination with the prevalence of the infectious agent, is often used to calculate the number of animals necessary for testing (Nicklas et al. 2002). The relatively low sensitivity of many diagnostic methods in fish is a major problem and results in many false negative results. This is a particular challenge when attempting detection of infectious agents in subclinically infected fish, as described below. Combinations of different tests are therefore frequently used for diagnostic purposes in fish.

There are many fish diseases where the cause and pathogenesis are not fully understood and this makes diagnosis difficult. In some cases, the diagnosis has to be based on macroscopic or microscopic changes alone (Ferguson et al. 1990). Crossreactions are often observed when using methods such as immunohistochemistry with polyclonal antisera. When using molecular biological methods such as polymerase chain reaction (PCR) for detection of pathogens, a discussion may quickly arise as to whether the agent detected is the cause of the disease or a subclinical carrier state. Enzyme-linked immunosorbent assay (ELISA) testing for antibody response may lead to similar discussions as to whether or not the fish is still infected with the pathogen. Challenge trials may be necessary to distinguish between similar strains of an agent (Santi et al. 2004). In some fish diseases, electron microscopy has to be used (Eliassen et al. 2004); this is a very time consuming and often unreliable method for detection.

Since the body temperature of most fish varies with water temperature, fish pathogens often show adaptation to a wide temperature range. This poses challenges 
when cultivating bacteria. Subclinical bacterial infections are also relatively common (Hiney 1995), so bacterial detection should be combined with other findings to interpret their relative importance.

The source of infectious fish agents is often not well documented and all possible sources (fish, personnel, water, feed or inanimate objects) should therefore be investigated. Hygiene routines and protocols for preventive medicine must be individually designed for each facility, fish species and type of experiment.

\section{Fish}

Most fish for research are still obtained from commercial fish farms, while a few laboratory facilities hatch and breed their own fish. As there is a risk that the fish are or have been infected by one or more pathogens before the start of the trial, monitoring should start a considerable time before the start of the experiment. If possible, the parent broodfish should be examined for vertically transmitted pathogens.

\section{Feed}

Some marine fish larvae require live feed such as artemia, rotifers and other zooplankton in their early stages. These organisms may carry many types of pathogens and good hygiene during zooplankton production is essential. Large numbers of bacteria that are normally nonpathogenic to zooplankton have caused major problems such as gill inflammation, enteritis and dermatitis in the production of fish larvae from several species including cod, halibut and turbot. These organisms may also make the fish larvae more susceptible to other diseases such as viral encephalopathy and retinopathy (Johansen et al. 2004).

Some fish species are still fed occasionally with frozen or fresh fish material. This can be a major source of infection with, for example, VHS-virus, Mycobacterium spp. and the parasite Ichthyophonus hoferi. If possible, experimental fish should be fed only commercial dried feed both prior to and during the trial.

It is also important to note that the nutritional status of the fish and feeding regime may have a major effect on the outcome of infectious diseases. In some cases, starving fish drastically lowers the mortality rate of the disease (Damsgård et al. 2004). Little is known about the basic mechanisms behind this starvation effect. An increased knowledge on how sick fish should be treated and fed is important to improve their welfare.

\section{Land-based experimental facilities}

In land-based experimental facilities, it is possible to construct strict hygiene barriers between different fish groups. Each tank should be equipped with separate equipment for cleaning and other routine tasks. Shared equipment should be thoroughly disinfected after use. A physical barrier between tanks may not be necessary if there is no risk of splash contamination. Footbaths and other systems for disinfection and/or change of clothing should be provided if necessary, as well as systems to avoid unnecessary personnel traffic.

Prior to initiation of the experiment, pipework should be cleaned and disinfected. Incoming water may be filtered and disinfected by ultraviolet (UV) or ozone treatment, but totally sterile water is often not obtainable. Ozone is beneficial to water quality as it not only inactivates microorganisms but also oxidizes nitrite to nitrate and breakes relatively non-biodegradable refractory organic compounds into smaller, more biogradable, compounds. In seawater, ozone treatment may result in the release of oxidants, including toxic bromates which must be removed (Crecelius 1979). Ozone is directly toxic to fish and should be removed by, for example, UV light treatment

(Summerfelt et al. 2004).

Testing of water for all potential pathogens is not normally feasible. Tests for the total number of bacteria (total cell count) or for an indicator organism before and after disinfection are therefore most often used. The choice of the indicator organism needs 
to be considered in relation to the fish species, local disease situation and available tests. Norwegian legislation, for example, requires disinfectant systems capable of a $3 \log _{10}$ reduction of Aeromonas salmonicida subsp. salmonicida and IPN-virus in research stations holding salmonids or freshwater fish. As far as discharged water is concerned, research stations assigned for challenge trials in category A need to show a minimum of $5 \log _{10}$ reduction of IPN-virus, while stations only assigned to challenge trials in category B and C need to show a $5 \log _{10}$ reduction of Yersinia ruckeri.

\section{Open-water systems}

Systems comprising normal farming pens are often used for large-scale experiments, both in freshwater and saltwater. Hygienic barriers separating the fish from wild populations are then often impossible to construct. As in land-based facilities, unnecessary personnel traffic should be avoided and changing facilities provided if considered necessary. Water treatment and regulation are not possible, so the risks of infectious disease agents gaining access to the trial have to be taken into account.

\section{Diseases}

The classical definition of a disease is a finite abnormality of structure or function with clinical signs (Stedman 1990), but today the definition is often widened to include also subclinical infections. Situations in which the animals do not perform or produce at expected levels may also be defined as a disease state (Blood \& Studdert 1993). The term 'clinical disease' is therefore used here to refer to situations where fish show clinical signs of disease.

Focus should be placed not only on the detection of disease but also on how it may affect the results of experimental trials. The stage and degree of disease are therefore of major importance. An outbreak of clinical disease may ruin the outcome of the trial, while a subclinical infection or suboptimal nutrition may have only minor effects, depending on the aim of the experiment.
Detection of both non-infectious and infectious diseases in clinically healthy fish may require testing of a large number of fish. Detection is normally easier in dead or moribund fish, so all these animals should be examined, since the findings may provide valuable information on the health status of the whole group.

\section{Infectious diseases}

The best way to avoid an infectious disease is of course to avoid the infectious agent, as discussed earlier. In some cases, this is not possible and vaccination is then often used to avoid the disease. Some vaccines may prevent an infection, but most only prevent or reduce the clinical manifestations of infection. Vaccinated fish may therefore still be infected, but the prevalence of clinical disease in these fish is much lower.

Infections in vaccinated fish may still have a major effect on the immune and health status of the fish, which in turn may have an effect on the outcome of the research results. Monitoring of infectious agents should therefore not be terminated when fish are vaccinated.

Sea lice infections with concomitant damage to the skin have a negative effect on the general health status of the fish and may allow entry of other pathogens. It has also been shown that sea lice infections cause a stress reaction in the fish with a possible subsequent suppression of the immune response (Mustafa et al. 1998). Sea lice infections are therefore a good example of conditions that may have an influence on the general health of the fish, even after the sea lice have been removed by treatment. Infections and medical treatments should be recorded for the whole lifespan of the fish, and not just for a short observation period immediately prior to the research period.

\section{Subclinical infections}

Some authors restrict the term 'asymptomatic' to human diseases and use the terms 'clinically inapparent' or 'covert' for infected animals with no signs of disease (Hiney et al. 1997). The most commonly 
used term in fish is 'subclinical', indicating that the fish are infected but show no clinical signs of disease. Subclinical infections may endure for a long time and are then called persistent infections. The term chronic is used to describe a disease that persists for a long time with little or no change in progression. Some authors restrict the term chronic to persistent infections that eventually are cleared, in contrast to latent infections that last throughout the lifetime of the host (Flint et al. 2000).

If subclinically infected fish are to be used in experimental trials, it is important to determine the possible outcomes of the infection. It is especially important to determine whether it may develop into a clinical disease and/or if it has emerged from an acute disease. If the subclinically infected fish shed the infectious agent, it is called a carrier infection and shedding may represent a direct threat to the rest of the fish group. It has been demonstrated that an infection may have either a positive or negative influence on the outcome of an additional infection in fish (Johansen \& Sommer 1995, LaPatra et al. 1995). This illustrates the difficulties involved when attempting to determine how an infection may influence the research results.

More information on the pathogenesis of persistent infections is of great importance for developing better detection methods. For example, a recent study showed that Atlantic halibut may be subclinically infected with IPN-virus for at least 18 months without showing any signs of disease (Gahlewat et al. 2004). Reverse transcription (RT)-PCR and standard virus isolation in cell culture detected a low number of IPNV-infected fish compared with new methods where adherent cells from kidney and blood were isolated and lysed before passage onto cell culture (Munro et al. 2004). This illustrates the complexity of virus detection in persistent infections and shows that a more sensitive test is often necessary in the persistent phase of the disease, compared with the acute phase.

To increase the chances of detection, a stress test that triggers the subclinical infection into an acute disease may be used.
Such a stress test has been established for detection of subclinical infections with, for example, Aeromonas salmonicida (Hiney 1995) and IPN-virus (Taksdal et al. 1998).

\section{Non-infectious diseases}

Non-infectious diseases may also have a major effect on the outcome of research, and monitoring of these conditions is therefore just as important as the infectious diseases.

\section{Malnutrition and starvation}

Optimal nutrition is critical for optimal growth, which is the main aim of fish farming. Much research has therefore been aimed at the optimization of commercial feed. Malnutrition is therefore not a common problem in those species that have been farmed for some time, but may occur in species such as cod where the industry is still under development. Different developmental stages (for example larvae and broodfish) and farming conditions (cold or warm water) may dictate different nutritional regimes. Optimized feed for all fish species at all ages and under all conditions is therefore important.

Malnutrition is still a major problem for marine fish larvae that require live zooplankton as their first feed. It is difficult to control the composition of the feed and the nutritional value may therefore vary considerably. Lack of pigmentation and incomplete metamorphosis have been linked to malnutrition in Atlantic halibut (Pittman 1991). Clinical signs of malnutrition may vary depending upon the type of deficiency (for example, vitamins or proteins) and species (Tacon 1992).

Fish are carnivorous, herbivorous or omnivorous. Marine proteins may soon be in short supply due to their inclusion in pig, chicken and fish feeds; so vegetable proteins are being sought as replacements in fish feed. This may have consequences for the future health and welfare of these fish.

\section{Deformities}

Minor deformities may not be detected in live fish and necropsy may be necessary. If 
the prevalence of the deformity is low, it may be best to examine the fish after completion of the trial.

Deformities in fish have been detected in many organs. The most common

deformities in salmonids are observed in the spinal cord and heart (Poppe et al. 1998, Baeverfjord et al. 1999, Kvellestad et al. 2000). Fish with major deformities are easy to avoid when selecting fish for research. In other cases, it may be difficult to determine where to draw the line between deformities and what is normal (Poppe et al. 2003, Figure 4).

\section{Inflammations}

Gills are very sensitive to any waterborne irritants and inflammation is therefore common. Irritation may be caused by parasites, particles, chemicals, metals, bacteria, fungi or viruses. Severe inflammation may be detected in fish with no clinical signs of disease, but a stress situation may provoke acute clinical signs in fish with chronic pathological changes in the gills.

Vaccination may cause mild to severe inflammatory reactions at the injection site and pathological changes have also been detected in other organs (Koppang et al. 2004, 2005). These side-effects may have a major influence on the health of the fish and

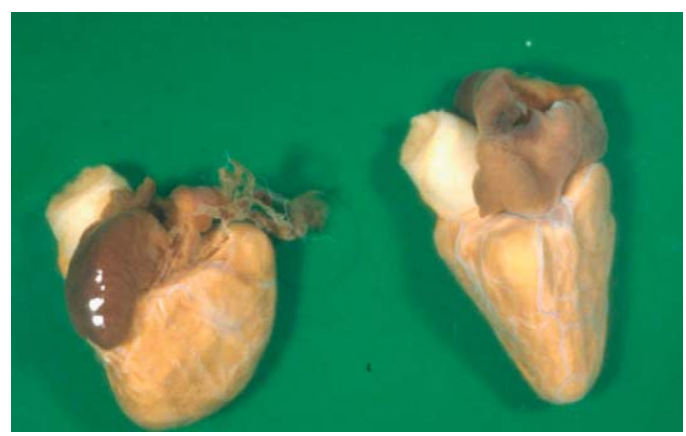

Figure 4 Hearts from rainbow trout, Oncorhynchus mykiss. The heart to the right has the normal pyramid shape that provides optimal blood flow, while the heart to the left is more spherical and less efficient as a pump. Both hearts were collected at the slaughterhouse from presumed healthy fish vaccinated fish should, if possible, not be used in research. If they have to be used, they should be examined for any side-effects.

Both the vaccine protocol and any detected side-effects should be reported and interpreted along with the research results.

Epicarditis (Johansen \& Poppe 2002) and cardiomyopathy syndrome (CMS) (Brun et al. 2003) are other examples of inflammatory conditions that may be detected in fish with no clinical signs of disease. The cause of these inflammations is still unknown, but may be because of as-yet unknown infectious agents or noninfectious causes such as malformations, malfunctions and metabolic disturbances. This cardiac pathology must be assumed to have a negative effect on the general health of the fish and may therefore influence research results.

Severe inflammations may be detected by macroscopic inspection of the organs, while moderate inflammations may require histopathological examinations. All organs should therefore be macroscopically examined for any signs of inflammation. Histopathological examination of all organs is often not possible for economical reasons, but some examinations need to be carried out to provide a total picture of the health status. In particular, histopathology of the gills may provide a good estimate of the water quality that the fish has been exposed to before the onset of the trial.

\section{Fish welfare}

The scientific study of animal welfare necessitates an objective means for deciding whether an animal is suffering or not. Suffering includes a wide range of unpleasant emotional states such as fear, boredom, pain and hunger. Welfare monitoring in animals may be performed by clinical observations, or indirectly by monitoring their environment (Wolffrom \& Santos 2005). Both health and welfare are used as general terms that may include each other; health monitoring is sometimes defined as part of the process of ensuring animal welfare, or vice versa. 
Welfare in fish has not been well defined and the ability of fish to feel pain and distress is still being debated (Rose 2002, Chandroo et al. 2004). The Fisheries Society of the British Isles has published a review on the subject, giving criteria for welfare in fish and including a summary of acute and chronic stress responses (FSBI 2002). The Society states that there is no simple link between physiological stress responses and welfare, but tertiary responses such as suppressed immune function, growth and reproduction indicate chronic stress and therefore poor welfare. A recent review of the literature on fish welfare (Huntingford et al. 2006) concludes that fish can experience fear-like states and that they probably have the capacity for suffering.

The price an animal is prepared to pay to attain or escape from a situation is often used as an index of how the animal thrives in its environment. Studies of the cognitive ability of fish have shown that they possess greater skills than previously believed (Braithwaite 2005). However, even with better knowledge of neurophysiology and cognitive abilities in fish, we will never truly know how a fish feels. Fish should be given the benefit of the doubt when knowledge is lacking. Animal research legislation and guidelines often refer to the avoidance of unnecessary suffering. For example, a method of killing fish such as suffocation, which is standard practice on fishing trawlers, is not acceptable in a research setting.

Even though our general knowledge of the stress response in fish is good, there are few methods available to document fluctuating stress levels in populations or individual fish (Bonga 1997). The way in which diseases affect the wellbeing and stress level of fish is still poorly understood (Damsgård et al. 2004). An apparently healthy fish in an adequate environment is not sufficient documentation of good fish welfare.

Behavioural changes are an important part of the stress response, since they enable animals to avoid or overcome the stressor. Even though fish have restricted opportunities to express their current internal state, changes in behaviour can be observed.
They may, for example, swim faster or slower, or in different patterns. Fish exhibit three main behaviour patterns: territorial, schooling or sedentary. Rainbow trout, for example, are territorial and therefore require space, which they defend by nipping the fins of other fish (Klontz 1995). Knowledge of this kind is essential when writing recommendations for fish density and tank design. There are undoubtedly large species differences in optimal stocking densities and more research is needed to determine how density affects the individual animals. Adequate knowledge of normal behaviour in the different fish species, together with knowledge of how to interpret abnormal behaviour, is therefore a prequisite for good welfare.

Fish showing signs of weakness will soon be attacked by predators, so the evolutionary process has favoured behaviour that does not indicate the presence of disease, and possibly also a higher threshold for suffering. Even fish with open wounds in the abdominal cavity and intestinal prolapse may not show overt behavioural signs of disease. Whether or not sick fish suffer can therefore not be determined by behaviour alone.

\section{Possibilities for future monitoring of welfare in fish}

Many of the parameters described below are commonly used for welfare monitoring in mammals. One of the aims of this section is to explain why these parameters are not used in fish monitoring today, and indicate how they may possibly be used in the future.

\section{Heart rate and respiration Heart and} respiration rates increase in stressful situations and these parameters are therefore often observed when monitoring the welfare of mammals. Such information is not, however, easy to register in fish. The respiratory rate may be monitored by looking at operculum ventilation rates, but this is only possible in small glass tanks and in fish of a certain size. Smart-tags that can measure heart rate and respiration in freely swimming fish in larger tanks are now being 
investigated (ETHIQUAL EU-project, http://www.seafoodplus.org/Project_5_2 ETHIQUAL.63.0.html). These new methods will improve the opportunity to investigate normal behaviour and stress responses in fish under farming or research conditions.

Blood samples Blood samples are usually taken from the caudal vein of fish, but procedures for sampling from many other arteries have also been described (Black 2000). Fluctuations in blood parameters have, however, made it more difficult to interpret these findings in fish compared to mammals. Better understanding of the circulatory system and stress in fish is necessary before blood samples can be used to a greater extent in the future.

Blood parameters may, for example, show large variations depending on how the blood samples are obtained. If 10 fish in a tank are sampled serially, the stress level in the last fish will be significantly higher than in the first animal (Roche \& Boge 1996). These workers also showed that a range of stressors (osmotic, thermic, physical and chemical) may cause varying effects on stress parameters (cortisol, blood glucose, haemoglobin and haematocrit).

The low blood pressure of fish may be one of the main explanations for the wide variations seen in many blood parameters. In mammals, blood is pumped under high pressure directly to the body organs. In fish, the blood is pumped to the gills under high pressure and then, after losing pressure in the capillary network, it flows under low pressure to the rest of the body. Some vessels are equipped with valves to ensure that the blood flows in the right direction (Figure 5). Contractions of the skeletal muscle help to pump the blood through the body. Venous pumps have been described in the tail, gills and the haemal canal. The blood pressure in the veins is so low that there may even be negative pressure. Anaesthesia has a major influence on the heart and it is important to make sure that blood pressure is adequate during blood sampling.

Guidelines for bleeding mammals often quote $10 \%$ of the circulating blood volume

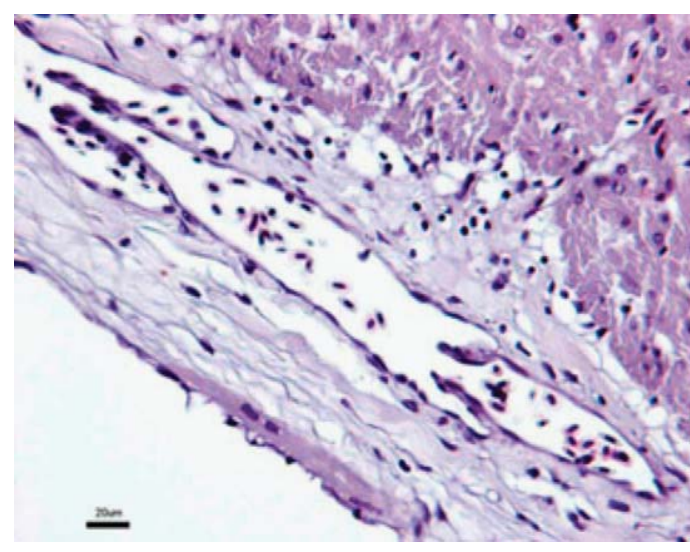

Figure 5 Histology of the coronary blood vessel in Atlantic salmon, Salmo salar, showing two pairs of valves that ensures that the blood flows in the correct direction

as a rough guide for one bleed from healthy animals, which may be repeated every 3-4 weeks (BVA/FRAME/RSPCA/UFAW Joint Working Group on Refinement 1993). There are few published estimates of circulating blood volume or guidelines for bleeding fish. The volume of blood in fish is normally estimated to be $2-5 \%$ of body weight and the CCAC guidelines recommend that no more than $1 \mathrm{~mL}$ blood should be sampled per kilogram body weight without killing the fish. This is quite a high figure compared to mammals.

The species, temperature and other parameters such as the presence of disease may of course influence these estimates.

The amount of circulating blood in fish may be low and may not be representative of the total blood volume. When the fish is resting, the spleen may contain a large amount of blood, whereas this blood will be available in the general circulation in a stressful situation. Likewise, stress will result in a diversion of blood flow from the intestinal organs to the skeletal muscle to support the 'fight or flight' mechanisms. Research in fish is needed to provide better estimates for the maximum amount of blood that should be sampled and this is especially important when serial sampling is planned.

Blood samples are usually taken from the main circulatory system, but fish also have a secondary system with a separate capillary network, which so far has been detected in 
gills, skin and intestinal organs (Iwama \& Farrell 1998). The composition and amount of blood in this secondary system is highly dependent upon the stress level of the fish. It may contain very few blood cells with large amounts of plasma if stress levels are high. The function of this system is not totally understood, but it is possibly related to the balance of ions and water. Stress may therefore have a major effect on blood parameters. It is also important that water quality is within the optimal range, to avoid any switch in the circulation due to conditions such as hypoxia, high salinity or low $\mathrm{pH}$.

One solution to the problems with blood sampling can be to sample the tank water instead. Detection methods for steroids in the water have been shown to correlate with the level of steroids in the blood of the fish (Scott et al. 2001, Ellis et al. 2004).

The skin The first organ to show any signs of distress in mammals is often the skin, and the condition of the skin and fur are often used as indicators of health and welfare. The skin and especially the mucus layer of fish may also provide valuable information about the wellbeing of the animal. Fish used in experimental trials should have intact skin and mucus without any signs of lesions.

Changes in the environment may exert an influence on several factors in the mucus such as its biochemical profile and bacterial flora (Fast et al. 2002). Acute stress alone, without physical trauma or pathogens, has been shown to cause skin ulceration in fish (Noga et al. 1998). The mucus is also the first line of defence against several infections, so detection of changes in the mucus may indicate the presence of pathogens. Improvements in our knowledge of the mucus layer may therefore be useful for monitoring both health and welfare and an EU research project has started to look into this field (FAIR-CT98-4217, http://www. cordis.lu/data/PROJ_FAIR/ACTIONeq DndSESSIONeq16683200595ndDOCeq4nd TBLeqEN_PROJ.htm).

Faeces Diarrhoea or other changes in faecal consistency or composition may be indica- tions of poor health and/or welfare. In fish, faeces are voided into the water and changes are therefore not normally registered as they are in mammals, except in extreme situations. Fish faeces should be monitored either by analyses of the water or by collecting intestinal samples (Black 2000). This type of examination is commonplace in feeding trials and parasitological research, but is seldom performed as part of a general health investigation, largely due to the lack of knowledge on how to interpret the results. Furthermore, the collection of intestinal samples may be a stressful process in itself. To avoid unnecessary stress, it should not be used routinely, but be limited to situations where there is concern about the health status of the fish.

\section{Asymmetry and deformities Stress in} broodstock fish may result in an increased incidence of deformities and asymmetry in their offspring (Eriksen et al. 2006). Stressors such as hypothermia, hypoxia, pathogens, suboptimal $\mathrm{pH}$, salinity, light and malnutrition have been shown to cause asymmetry (Koumoundouros et al. 2001). Deformities have been linked to poor rearing conditions (Boglione et al. 2001). Further studies are needed to establish whether or not asymmetry can be used as an indicator of fish welfare.

\section{Molecular biological methods Several} research groups are now focusing on the development of molecular methods, not only to detect pathogens but also to investigate how infectious agents and other stress factors influence the fish (Gornati et al. 2005). These methods will enable new opportunities for monitoring the health and welfare of fish. Gornati et al. (2005) investigated gene expression in fish groups reared at different population densities and detected changes in six genes that will be further investigated as possible welfare indicators. The EU research programme 'WEALTH Welfare and health in aquaculture' (http:// europa.eu.int/comm/research/fp6/ssp/ wealth_en.htm) focuses on detection of molecular biological parameters in fish that 
have been exposed experimentally to a range of stressors, including inflammatory processes.

Basic research on stress proteins in fish using molecular biological methods has been performed for many years, with the aim of using fish as biomarkers of cellular stress (Iwama et al. 1998). Increased expression of metallothionein in liver, gills and the intestine has been observed following thermic stress (Cleef-Toedt et al. 2001). The results will be investigated further in an attempt to establish fish models as biomarkers of environmental exposure to chemical stressors such as toxic metals. This type of basic research may also provide knowledge of stress markers that may be useful in documenting the wellbeing of fish.

\section{Reporting results}

To provide a total picture of research results, it is important to report the health and welfare status of the fish. Guidelines for monitoring of health and welfare should provide a plan describing how this is to be reported. The examination methods used should be stated, as well as the results of the tests. Even if interpretations of the findings are uncertain, they should be reported to aid future research. A long-term investigation covering the whole lifespan of the fish provides more information than a snapshot report at the time of the research. A general checklist of the information that should be reported from fish research has already been published (Brattelid \& Smith 2000), but health monitoring should be added to this list.

When choices have been made between, for example, species and rearing conditions, the reasons for the choice should be documented. Disease outbreaks may vary greatly between species and locations. Each research facility may therefore need a checklist based on the current disease situation in the fish species they are using, adapted to local geographical conditions. It is important to remember, however, that the aim of guidelines is to promote international harmonization.

\section{Checklist}

- Selection of fish

- Choice of fish species, strain, stock, breeding programme, genetic modification, development stage, age, sex (if possible)

- External selection criteria: size, deformities, scars

- Health status, both at the farm providing eggs and of the fish themselves

- Quarantine

- Length of observation period

- Type of monitoring

- The environment

- Parameters to be monitored including choice of methods

- Measurements, fluctuations and duration

- Holding facilities

- Handling procedures

- Pathogens

- Preventive measures to avoid pathogens

- List of pathogens to be monitored including choice of methods

- List of pathogens to avoid

- List of clinical diseases to avoid

- Acute or chronic stage of the disease

- Number of fish needed for necropsy and testing

- How to interpret positive detections of pathogens and/or diseases

- Medical treatments allowed

- Non-infectious diseases

- List of diseases to be monitored including choice of methods

- Number of fish needed for necropsy and testing

- Evaluation of nutritional status

- List of diseases and conditions to avoid

- How to interpret any positive detections

- Welfare

- Behaviour of the fish

- Density of fish

- Other documentations of the wellbeing of the fish

- Interpretation of the results from the health and welfare monitoring in correlations to the aims and the results of the research. 


\section{References}

Alestrom P (2004) Zebrafish model - from biomedicine to aquaculture. Keynote Lecture at European Aquaculture Society, Special Publication 34, 10-17

Baeverfjord G, Lein I, Asgard T, Rye M, Storset A (1999) Vertebral deformations induced by high temperatures during embryogenesis in Atlantic salmon (Salmo salar L.). EAS Special Publication 27, 6-7

Benfey TJ, Biron M (2000) Acute stress response in triploid rainbow trout (Oncorhynchus mykiss) and brook trout (Salvelinus fontinalis). Aquaculture 184, 167-76

Black MC (2000) Collection of body fluids. In: The Laboratory Fish (Ostrander GK, eds). Baltimore: Academic Press, 513-27

Blood DC, Studdert P (1993) Bailliêre's Comprehensive Veterinary Dictionary. 3rd edn. London: Bailliere Tindall

Boglione C, Gagliardi F, Scardi M, Cataudella S (2001) Skeletal descriptors and quality assessment in larvae and post-larvae of wild and reared gilthead bream (Sparus aurata L). Aquaculture 192, 1-22

Bonga SEW (1997) The stress response in fish. Physiological Reviews 77, 591-625

Braithwaite VA (2005) Cognitive ability in fish. Fish Physiology 24, 1-37

Brattelid T, Smith AJ (2000) Guidelines for reporting the results of fish experiments. Laboratory Animals 34, 131-5

Braunbeck T, Böttcher M, Hollert H, et al. (2004) Towards an alternative for the acute fish $\mathrm{LC}_{50}$ test in chemical assessment: the fish embryo toxicity test goes multi-species - an update. LINZ 1, 87-102

Brun E, Poppe TT, Skrudland A, Jarp J (2003) Cardiomyopathy syndrome in farmed Atlantic salmon Salmo salar: occurrence and direct financial losses for Norwegian aquaculture. Diseases of Aquatic Organisms 56, 241-7

BVA/FRAME/RSPCA/UFAW Joint Working Group on Refinement (1993) Removal of blood from laboratory mammals and birds. First Report of the BVA/ FRAME/RSPCA/UFAW Joint Working Group on Refinement. Laboratory Animals 27, 1-22

Canadian Council on Animal Care (2005) Guidelines on the care and use of fish in research, teaching and testing. http://www.ccac.ca

Casebolt DB, Speare DJ, Horney BS (1998) Care and use of fish as laboratory animals: current state of knowledge. Laboratory Animal Science 48, 124-36

Chandroo KP, Yue S, Moccia RD (2004) An evaluation of current perspectives on consciousness and pain in fishes. Fish and Fisheries 5, 281-95

Cleef-Toedt K, Kaplan L, Crivello JF (2001) Killifish metallthionein messenger RNA expression following temperature pertubation and cadmium exposure. Cell Stress and Chaperones 6, 351-9

Council of Europe (2006) European Convention for the Protection of Vertebrate Animals used for
Experimental and other Scientific Purposes (ETS 123). Revision of Appendix A adopted by the Multilateral Consultation on 15 June 2006, Strasbourg. http://www.coe.int/t/e/legal_ affairs/legal_co\%2Doperation/biological_ safety\%2C_use_of_animals/laboratory_animals/ draft\%20revision \%20of\%20Appendix\%20A.asp\#

TopofPage

Crecelius EA (1979) Measurements of oxidants in ozonized seawater and some biological reactions. Journal of Fisheries Research Board of Canada Bulletin 36, 1006-8

Damsgård B, Sørum U, Uglestad I (2004) Effects of feeding regime on susceptibility of Atlantic salmon (Salmo salar) to cold water vibriosis. Aquaculture 239, 37-46

Dawe CJ, Couch JA (1984) Debate: mouse versus minnow: the future of fish in carcinogenicity testing. National Cancer Institute Monograph 65, 223-35

DEFRA (2003) Combating Fish Disease - an Explanation of the Controls on Notifiable Fish Diseases in Great Britain and Advice on Steps to Prevent the Spread of Disease. UK: Department for Environment, Food \& Rural Affairs

DeTolla LJ, Srinivas S, Whitaker BR, et al. (1995) Guidelines for the care and use of fish in research. Institute for Laboratory Animal Research Journal 37, 1-19

Eliassen TM, Solbakk IT, Evensen O, Gravningen K (2004) Isolation of heart and skeletal muscle inflammation virus (HSMIV) from salmon. International Symposium on Viruses of Lower Vertbrates (ISVLV). 19-22 September 2004, Hakodate, Hokkaido, Japan

Ellis T, James JD, Stewart C, Scott AP (2004) A noninvasive stress assay based upon measurement of free cortisol released into the water by rainbow trout. Journal of Fish Biology 65, 1233-52

Eriksen MS, Bakken M, Espmark A, Braastad BO, Salte R (2006) Prespawning stress in farmed Atlantic salmon Salmo salar: maternal cortisol exposure and hyperthermia during embryonic development affect offspring survival, growth and incidence of malformations. Journal of Fish Biology 69, 114-29

Fast MD, Sims DE, Burka JF, Mustafa A, Ross NW (2002) Skin morphology and humoral non-specific defence parameters of mucus and plasma in rainbow trout, coho and Atlantic salmon. Comparative Biochemistry and Physiology 132, 645-57

Ferguson HW (1989) Systemic Pathology of Fish. Ames: Iowa State University Press

Ferguson HW, Poppe TT, Speare DJ (1990) Cardiomyopathy in farmed Norwegian salmon. Diseases of Aquatic Organisms 8, 225-31

Flint SJ, Racaniello VR, Enquist LW, Skalka AM, Krug RM (2000) Virology. Molecular Biology, Pathogenesis and Control. Washington: ASM Press 
FSBI (2002) Fish welfare. Briefing Paper 2. Fisheries Society of the British Isles. http://www.le.ac.uk/ biology/fsbi/welfare.pdf

Gahlewat SK, Munro ES, Ellis AE (2004) A nondestructive test for detection of IPNV-carriers in Atlantic halibut, Hippoglossus hippoglossus. Journal of Fish Diseases 27, 233-9

Gjedrem T, Gjøen HM (1995) Genetic variation in susceptibility of Atlantic salmon, Salmo salar L., to furunculosis, BKD and coldwater vibriosis. Aquaculture Research 26, 129-34

Gornati R, Gualdoni R, Cavaliere $\mathrm{G}$, Terova G, Saroglia M, Bernardini G (2005) Molecular biology and fish welfare: a winning combination. Aquaculture International 13, 51-5

Grimholt U, Larsen S, Nordmo R, et al. (2003) MHC polymorphism and disease resistance in Atlantic salmon; facing pathogens with single expressed major histocompatibility class I and class II loci. Immunogenetics 55, 210-19

Grossblatt N (1996) Guide for the Care and Use of Laboratory Animals. Washington, DC: National Academy Press

Hiney M (1995) Detection of stress inducible furunculosis in salmonids vaccinated with water and oil based furunculosis vaccines. Bulletin of European Association of Fish Pathologists 15, 98-9

Hiney M, Smith P, Bernoth EM (1997) Covert Aeromonas salmonicida infections. In: Furunculosis (Bernoth EM, Ellis AE, Midtlyng P, Olivier G, Smith P, eds). London: Academic Press, 54-97

Huntingford FA, Adams C, Braithwaite VA, et al. (2006) Current issues in fish welfare. Journal of Fish Biology 68, 332-72

Iwama GK, Farrell AP (1998) Disorders of the cardiovascular and respiratory systems. In: Fish Diseases and Disorders. Non-Infectious Disorders (Leatherland JF, Woo PTK, eds). Canada: CABI Publishing, 245-78

Iwama GK, Thomas PT, Forsyth RB, Vijayan MM (1998) Heat shock proteins expression in fish. Reviews in Fish Biology and Fisheries 8, 35-56

Johansen LH, Sommer A-I (1995) Multiplication of infectious pancreatic necrosis virus (IPNV) in head kidney and blood leukocytes isolated from Atlantic salmon, Salmo salar L. Journal of Fish Diseases 18, $147-56$

Johansen R, Poppe TT (2002) Pericarditis and myocarditis in farmed Atlantic halibut Hippoglossus hippoglossus. Diseases of Aquatic Organisms 49, $77-81$

Johansen R, Sommerset I, Tørud B, et al. (2004) Characterization of nodavirus and viral encephalopathy and retinopathy (VER) in farmed turbot Scophthalmus maximus. Journal of Fish Diseases 27, 591-601

Kane AS, Gonzalez JF, Reimschuessel R (1996) Fish and amphibian models used in laboratory research. Lab Animal 25, 33-8
Klontz GW (1995) Care of fish in biological research. Journal of Animal Science 73, 3485-92

Kolstad K, Heuch PA, Gjerde B, Gjedrem T, Salte R (2005) Genetic variation in resistance of Atlantic salmon (Salmo salar) to the salmon louse Lepeoptheirus salmonis. Aquaculture 247, $145-51$

Koppang EO, Haugarvoll E, Hordvik I, Aune L, Poppe TT (2005) Vaccine-associated granulomatous inflammation and melanin accumulation in Atlantic salmon, Salmo salar L., white muscle. Journal of Fish Diseases 28, 13-22

Koppang EO, Haugarvoll E, Hordvik I, Poppe TT, Bjerkas I (2004) Granulomatous uveitis associated with vaccination in the Atlantic salmon. Veterinary Pathology 41, 122-30

Koumoundouros G, Divanach P, Kentouri M (2001) The effect of rearing conditions on development of saddleback syndrome and caudal fin deformities in Dentex dentex (L.). Aquaculture 200, 285-304

Kvellestad A, Høie S, Thorud K, Tørud B, Lyngøy A (2000) Platyspondyly and shortness of vertebral column in farmed Atlantic salmon Salmo salar in Norway - description and interpretation of pathologic changes. Diseases of Aquatic Organisms 39, 97-108

LaPatra SE, Lauda KA, Jones GR (1995) Aquareovirus interference mediated resistance to infectious hematopoietic necrosis virus. Veterinary Research 26, 455-9

LaPatra SE, Barone L, Jones GR, Zon LI (2000) Effects of infectious hematopoietic necrosis virus and infectious pancreatic necrosis virus infection on hematopoietic precursors of the zebrafish. Blood Cells Molecules and Diseases 26, 445-52

Lymbery P (2002) In Too Deep - The Welfare of Intensively Farmed Fish. Petersfield, Hampshire: Compassion in World Farming Trust

May EB, Bennett RO, Lipsky MM, Reimschuessel R (1987a) Using fish as models in biomedical research. Part 1. Lab Animal 16(4), 23-8

May EB, Bennett RO, Lipsky MM, Reimschuessel R (1987b) Using fish as models in biomedical research. Part 2. Lab Animal 16(5), 25-31

Melby EC, Balk MW (1983) The Importance of Laboratory Animal Genetics, Health and the Environment in Biomedical Research. Orlando: Academic Press

Munro ES, Gahlawat SK, Ellis AE (2004) A sensitive non-destructive method for detecting IPNV carrier Atlantic salmon, Salmo salar L., by culture of virus from plastic adherent blood leucocytes. Journal of Fish Diseases 27, 129-34

Mustafa A, Bower J, MacWilliams C, Fernandez N, Conboy G, Burka JF (1998) Effect of sea lice infection on macrophage functions in Atlantic salmon. Bulletin of Aquaculture Association of Canada 2, 90-2

Nicklas W, Baneux P, Boot T, et al. (2002) Recommendations for the health monitoring of rodent 
and rabbit colonies in breeding and experimental units. Laboratory Animals 36, 20-42

Nilsson J (1992) Genetic variation in resistance of Arctic char to fungal infection. Journal of Aquatic Animal Health 4, 126-8

Noga EJ, Botts S, Yang MS, Avtalion R (1998) Acute stress causes skin ulceration in striped bass and hybrid bass (Morone). Veterinary Pathology 35, 102-7

OIE (2003) Manual of Diagnostic Tests for Aquatic Animals. 4th edn. Paris: Office International des Epizooties. http://www.oie.int/eng/normes/ en_acode.htm

OIE (2005) Aquatic Animal Health Code. 8th edn. Paris: Office International des Epizooties. http:// www.oie.int/eng/normes/en_acode.htm

Okamoto N, Tayama T, Kawanobe M, Fujiki N, Yasuda Y, Sano N (1993) Resistance of a rainbow trout strain to infectious pancreatic necrosis. Aquaculture 117, 71-6

Ostrander GK (2000) The Laboratory Fish. Baltimore: Academic Press

Phelan PE, Pressley ME, Witten PE, Mellon MT, Blake S, Kim CH (2005) Characterization of snakehead rhabdovirus infection in zebrafish (Danio rerio). Journal of Virology 79, 1842-52

Pittman K (1991) Aspects of the early life history of the Atlantic halibut, Hippoglossus hippoglossus (PhD thesis). University of Bergen

Poole T (1999) UFAW Handbook on the Care and Management of Laboratory Animals. Amphibious and Aquatic Vertebrates and Advanced Invertebrates. 7th edn. Essex: Blackwell Science

Poppe TT, Johansen R, Gunnes G, Tørud B (2003) Heart morphology in wild and farmed Atlantic salmon Salmo salar and rainbow trout Oncorhynchus mykiss. Diseases of Aquatic Organisms 57, 103-8

Poppe TT, Midtlyng P, Sande RD (1998) Examination of abdominal organs and diagnosis of deficient septum transversum in Atlantic salmon (Salmo salar L.) using diagnostic ultrasound imaging. Journal of Fish Diseases 21, 67-72

Powers DA (1989) Fish as model systems. Science 246, $352-8$

Rehbinder C, Baneux P, Forbes D, et al. (1998) FELASA recommendations for the health monitoring of breeding colonies and experimental units of cats, dogs and pigs. Laboratory Animals 32, 1-17

Roberts RJ (1989) Fish Pathology. London: Bailliere Tindall

Roche H, Boge G (1996) Fish blood parameters as potential tool for identification of stress caused by environmental factors and chemical intoxication. Marine Environmental Research 41, 27-43
Rose JD (2002) The neurobehavioral nature of fishes and the question of awareness and pain. Reviews in Fisheries Science 10, 1-38

Ryder K (2005) Challenges of applying humane endpoints in fish. 2nd International Conference on the Use of Humane Endpoints in Animal Experiments for Biomedical Research. 20-21 August 2005, Berlin, Germany

Santi N, Vakharia VN, Evensen O (2004) Identification of putative motifs involved in the virulence of infectious pancreatic necrosis virus. Virology 322, $31-40$

Schwedeler TE, Johnson SK (2000) Responsible care and health maintenance of fish in commercial aquaculture. Animal Welfare Information Centre Bulletin, 10. http://www.nal.usda.gov/awic/ newsletters/v10n3/10n3schw.htm

Scott AP, Pinillos M, Ellis T (2001) Why measure steroids in fish plasma when you can measure them in the water? In: Perspectives in Comparative Endocrinology (Goos T, Rastogi RK, Vaudry H, Pierantoni R, eds). Bologna: Monduzzi Editore, $1291-5$

Stedman TL (1990) Stedman's Medical Dictionary. 25th edn. Baltimore: Williams \& Wilkins

Summerfelt ST, Sharrer MJ, Hollis J, Gleason LE, Summerfelt SR (2004) Dissolved ozone destruction using ultraviolet irradiation in recirculating salmonid culture system. Aquacultural Engineering 32, 209-23

Tacon AGJ (1992) Nutritional fish pathology. Morphological signs of nutrient deficiency and toxicity in farmed fish. FAO Fish Technical Paper 330, 1-75

Taksdal T, Ramstad A, Stangeland K, Dannevig BH (1998) Induction of infectious pancreatic necrosis (IPN) in covertly infected Atlantic salmon, Salmo salar L., post-smolts by stress exposure, by injection of IPN virus and by cohabitation. Iournal of Fish Diseases 21, 193-204

Thorgaard GH (1986) Ploidy manipulation and performance. Aquaculture 57, 57-64

Use of Fishes in Research Committee (2004) Guidelines for the Use of Fishes in Research. Maryland: American Fisheries Society. http://www.fisheries. org/html/Public_Affairs/Sound_SCience/ Guidelines2004.shtml

Westerfield M (2000) The Zebrafish Book, A Guide for the Laboratory Use of Zebrafish (Danio rerio). 4th edn. Eugene: University of Oregon Press

Winton JR (2001) Fish health management. In: Fish Hatchery Management (Wedemeyer G, ed). Maryland: American Fisheries Society, 559-640

Wolffrom T, Santos ML (2005) Farmed Fish and Welfare. European Commision: Directorate General Fisheries and Maritime Affairs, 1-39 